\title{
Astrophysics and Space Science Library
}

\section{Proceedings $1.8, \ldots$.}

\section{Hydrogen}

Defleient Stars andrelated ny

Objects सhAS

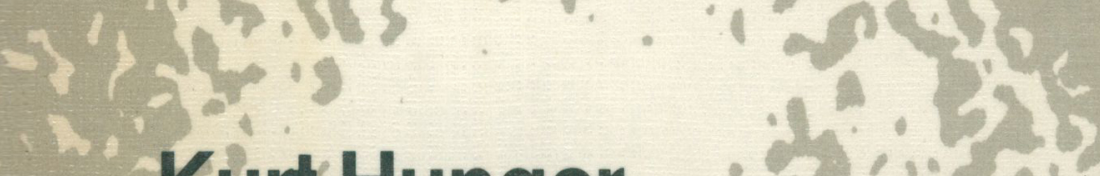

Kurt Hunger, - 3 un is

Detlef Schönberner and

- N. Kameswara Rao (Editors)

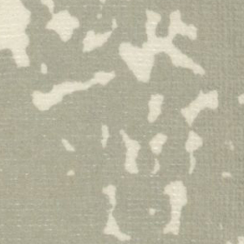

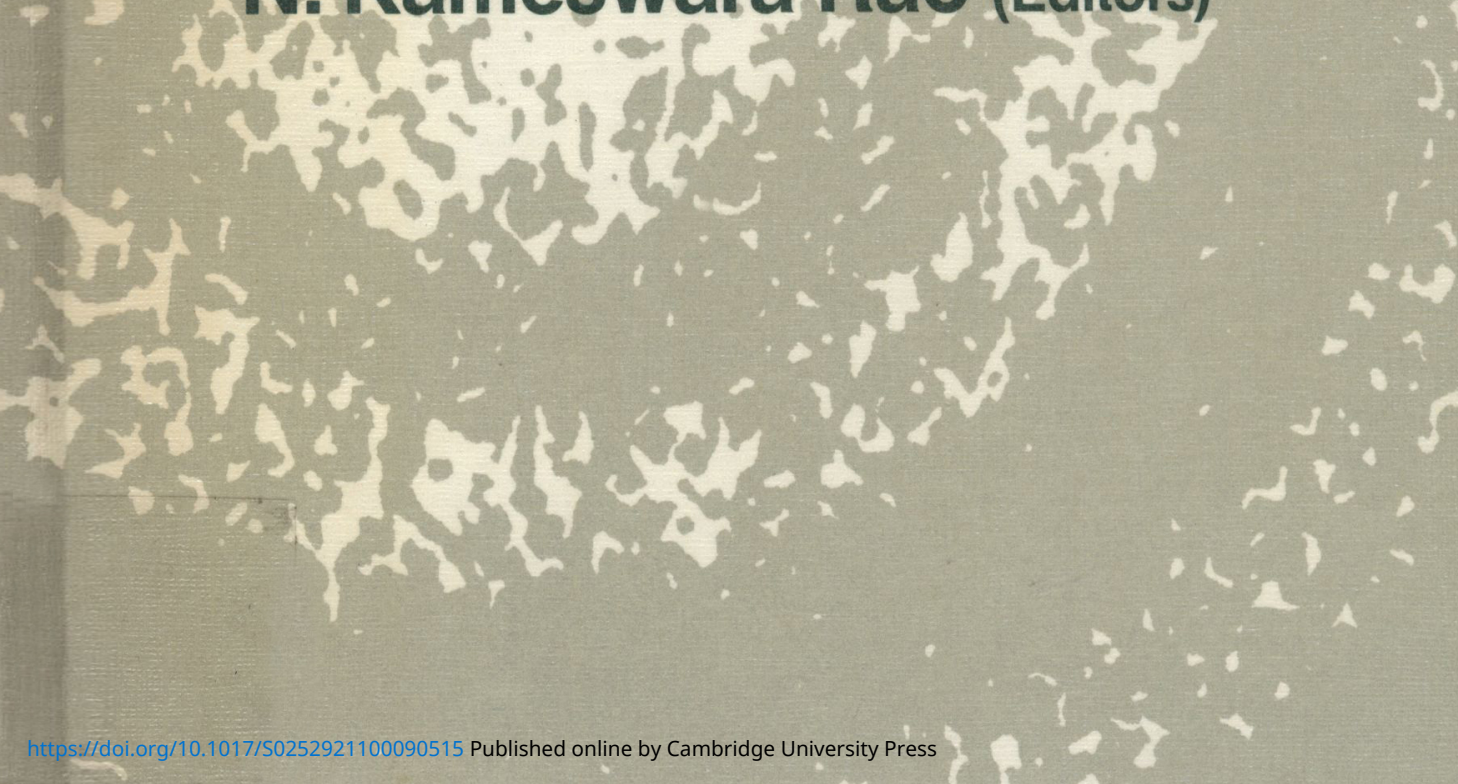

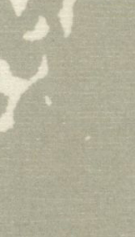


HYDROGEN DEFICIENT STARS AND RELATED OBJECTS 


\title{
ASTROPHYSICS AND SPACE SCIENCE LIBRARY
}

\author{
A SERIES OF BOOKS ON THE RECENT DEVELOPMENTS \\ OF SPACE SCIENCE AND OF GENERAL GEOPHYSICS AND ASTROPHYSICS \\ PUBLISHED IN CONNECTION WITH THE JOURNAL \\ SPACE SCIENCE REVIEWS
}

\section{Editorial Board}

R.L.F. BOYD, University College, London, England

W. B. BURTON, Sterrewacht, Leiden, The Netherlands

L. GOLDBERG, Kitt Peak National Observatory, Tucson, Ariz., U.S.A.

C. DE JAGER, University of Utrecht, The Netherlands

J. KLECZEK, Czechoslovak Academy of Sciences, Ondřejov, Czechoslovakia

Z. KOPAL, University of Manchester, England

R. LÜST, European Space Agency, Paris, France

L. I. SEDOV, Academy of Sciences of the U.S.S.R., Moscow, U.S.S.R.

Z. ŠVESTKA, Laboratory for Space Research, Utrecht, The Netherlands

\author{
VOLUME 128 \\ PROCEEDINGS
}




\title{
HYDROGEN \\ DEFICIENT STARS \\ AND RELATED OBJECTS
}

\author{
PROCEEDINGS OF THE 87TH COLLOQUIUM OF THE \\ INTERNATIONAL ASTRONOMICAL UNION \\ HELD AT MYSORE, INDIA, 10-15 NOVEMBER 1985
}

\author{
Edited by \\ KURT HUNGER \\ and \\ DETLEF SCHÖNBERNER \\ Institute for Theoretical Physics and Observatory, \\ University of Kiel, F.R.G. \\ and \\ N. KAMESWARA RAO \\ Indian Institute of Astrophysics, Bangalore, India
}

\section{REIDEL PUBLISHING COMPANY}

A MEMBER OF THE KLUWER

ACADEMIC PUBLISHERS GROUP

DORDRECHT / BOSTON / LANCASTER / TOKYO 
International Astronomical Union. Colloquium (87th : 1985 : Mysore, India)

Hydrogen deficient stars and related objects.

(Astrophysics and space science library; v. 128)

1. A stars-Congresses. 2. B stars-Congresses. 3. Cool starsCongresses. 4. White dwarfs-Congresses. 5. Cosmochemistry-

Congresses. I. Hunger, Kurt. II. Schönberner, Detlef. III. Kameswara

Rao, N. IV. Title. V. Series.

QB843.A12I57 $1985 \quad 523.8 \quad 86-17857$

ISBN 90-277-2326-5

Published by D. Reidel Publishing Company, P.O. Box 17,3300 AA Dordrecht, Holland.

Sold and distributed in the U.S.A. and Canada by Kluwer Academic Publishers, 101 Philip Drive, Assinippi Park, Norwell, MA 02061 , U.S.A.

In all other countries, sold and distributed by Kluwer Academic Publishers Group, P.O. Box 322, 3300 AH Dordrecht, Holland.

All Righț Reserved

(c) 1986 by D. Reidel Publishing Company, Dordrecht, Holland

No part of the material protected by this copyright notice may be reproduced or utilized in any form or by any means, electronic or mechanical including photocopying, recording or by any information storage and retrieval system, without written permission from the copyright owner

Printed in The Netherlands 


\section{INTRODUCTION}

W.P. BIDELMAN: Introductory comments

\section{BASIC DATA}

J.S. DRILLING: Basic data on hydrogen-deficient stars (Review)

J.S.DRILLING, U. HEBER: Radial velocities of extreme helium stars

\section{HOT EXTREME HELIUM STARS}

U. HEBER: Spectroscopic analyses of hot extreme helium stars (Review)

A.U. LANDOLT: Photometric properties of the extreme helium stars (Review)

U. HEBER, G. JONAS, J.S. DRILLING: High resolution spectroscopy of six new extreme helium stars

U. HEBER: Emission lines in high resolution spectra of extreme helium stars

C.S. JEFFERY: The peculiar spectrum of the extreme helium star BD $-9^{\circ} 4395$

A.E. LYNAS-GRAY, D. KILKENNY, I. SKILLEN, C.S. JEFFERY: Non-radial pulsations in the extreme helium star HD 160641

C.S. JEFFERY, P.W. HILL, K. MORRISON: The period of the extreme helium star $B D+1^{\circ} 4381$

C.S. JEFFERY, U. HEBER, P.W. HILL: A preliminary analysis of the pulsating extreme helium star V 652 Her $\left(B D+13^{\circ} 3224\right) \quad 101$

P.W. HILL, C.S. JEFFERY: The radial velocity curve of $V 652$ Her $\left(B D+13^{\circ} 3224\right)$

A.E. LYNAS-GRAY, D. KILKENNY: The light curve of the pulsating extreme helium star $\mathrm{BD}+13^{\circ} 3224$ : further evidence of a decline in the period decrease rate 
D.L. LAMBERT: The chemical composition of cool stars: II-the hydrogen deficient stars (Review)

M.W. FEAST: The RCB stars and their circumstellar material (Review)

A.V. RAVEENDRAN, N. KAMESWARA RAO, M.R. DESHPANDE, U.C. JOSHI,

A.K. KULSHRESTHA: Polarimetric observations of hydrogen deficient stars

A.E. ROSENBUSH: Distribution of light minima of $R$ Coronae Borealis type stars

S. GIRIDHAR, N. KAMESWARA RAO: Abundance analysis of $\mathrm{R} C r B$ variable UW Cen

N. KAMESWARA RAO, R. VASUNDHARA, B.N. ASHOKA: Spectrophotometric observations of $\mathrm{R}$ CrB during 1972, 74 minima

A.V. RAVEENDRAN, B.N. ASHOKA, N. KAMESWARA RAO: Photometric and radial velocity variations of $R \operatorname{CrB}$ near maximum light 191

R. SURENDIRANATH, K.E. RANGARAJAN, N. KAMESWARA RAO: Preliminary analysis of the broad He I emission lines in $\mathrm{R} C r B$

K. NANDY, N. KAMESWARA RAO, D.H. MORGAN: 3.0 to 3.5 micron spectrum of $V 348 \mathrm{Sgr}$ and $\mathrm{R} \mathrm{CrB}$

J.W. MENZIES: RY Sgr: Can the time of the next deep minimum be predicted?

W.A. LAWSON: RY Sgr: Pulsation related phenomenon

D. SCHÖNBERNER, U. HEBER: Anomalous UV-extinction and the effective temperature of $\mathrm{V} 348 \mathrm{Sgr}$

D. SCHÖNBERNER: On the mass and Iuminosity of $V 348 \mathrm{Sgr}$

D.H. MORGAN, K. NANDY, N. KAMESWARA RAO: The Large Magellanic Cloud R CrB star - HV 12842

\section{HYDROGEN DEFICIENT BINARIES}

M.J. PLAVEC: Hydrogen-poor binary stars (Review)

K. MORRISON, J.S. DRILLING, U. HEBER, P.W. HILL, C.S. JEFFERY: Photometric and spectroscopic variability of the hydrogen-deficient binary $C P D-58^{\circ} 2721$

P. NAGAR, K.D. ABHYANKAR: Hydrogen deficiency in Algol secondaries

\section{INTERMEDIATE HELIUM STARS}

K. HUNGER: Intermediate helium stars: Atmospheric parameters, oblique rotators and shells (Review)

P.K. BARKER: Magnetic fields and winds of the intermediate helium stars (Review)

A.P. ODELL, S.A. VOELS: Helium-rich stellar atmosphere models for $B$ stars

A.P. ODELL: Analysis of the helium strong star HD 37017

G. LANGHANS, U. HEBER: SB 939 - a new intermediate helium star at high galactic latitudes

J.M. MATTHEWS, R.W. SLAWSON, W.H. WEHLAU: Spectral variations of the rapidly oscillating Ap star HD 60435 
R.H. MÉNDEZ, C.H. MIGUEL, U. HEBER, R.P. KUDRITZKI: Helium rich subdwarf $O$ stars and central stars of planetary nebulae (Review)

U. HEBER, J.S. DRILLING, D. HUSFELD: UV- and visual spectroscopy of nine extremely helium rich subluminous 0-stars

D. HUSFELD, U. HEBER, J.S. DRILLING: NLTE-analysis of three extremely helium-rich O-type subdwarfs

S.R.POTTASCH, A. MAMPASO, A. MANCHADO, J. MENZIES: Hydrogen deficient planetary nebulae: preliminary results

J. LIEBERT: The origin and evolution of helium-rich white dwarfs (Review)

J. LIEBERT, F. WESEMAEL, C.J. HANSEN, G. FONTAINE, H.L. SHIPMAN, E.M. SION, D.E. WINGET, R.F. GREEN: Temperatures for hot and pulsating helium-rich (DB) white dwarfs obtained with the IUE observatory

I. BUES: Line band profiles in the spectra of cool magnetic helium-rich white dwarfs

K.R.N. KUTTY, T.M.K. MARAR, V.N. PADMINI, S. SEETHA, K. KASTURIRANGAN, U.R. RAO, J.C. BHATTACHARYYA, S. MOLIN, K. JAYAKUMAR: Detection of an extremely active state of AM Canum Venaticorum

VIII IRAS - RESULTS

H.J. WALKER: IRAS results for hydrogen deficient stars (Review)

\section{THEORY}

H. SAIO: Pulsations of hydrogen deficient stars (Review)

Y.A. FADEYEV: Theory of dust formation in R Coronae Borealis stars (Review)

G. MICHAUD: Diffusion and He overabundances: hydrodynamical implications (Review)

D. SCHÖNBERNER: Evolutionary status and origin of extremely hydrogen-deficient stars (Review)

A. TUTUKOV: On the origin of helium rich stars

\section{$X \quad$ APPENDIX}

J.S. DRILLING, P.W. HILL: Appendix A: A catalogue of hydrogendeficient stars 